\title{
Interdisciplinary Humanitarian Strategy and Technology of Students' Reading Activity Organization in the Pedagogical University
}

\author{
Lyudmila I. Zabara \\ Institute of Social Sciences \\ Ural State Pedagogical University, \\ Yekaterinburg, Russian Federation \\ e-mail: zabarali2011@gmail.com
}

\author{
Lilia N. Yakina \\ Information and Intellectual Center - Scientific Library \\ Ural State Pedagogical University \\ Yekaterinburg, Russian Federation \\ e-mail: lilia.yakina@yandex.ru
}

\author{
Liliya E. Zelenina \\ Institute of Foreign Languages \\ Ural State Pedagogical University \\ Yekaterinburg, Russian Federation \\ e-mail: zel-liliya@yandex.ru
}

\begin{abstract}
The article deals with theoretical aspects of reading's activity in the university library under the conditions of digital information culture and domination of impersonal communication. The necessity of humanization of library processes is proved. The positive influence on students' semantic reading is shown. To solve this task, it is necessary to introduce interdisciplinary approach in the educational environment. It includes dialogical, integrative, resource, value-oriented components. The specific of the strategy and practice of humanitarian technologies of the library-pedagogy were reflected in the development of technology of literature room-discussion. It is aimed at the increasing of values and semantic components of book communication with the reader. The realization of library humanitarian technology of room-discussion for young people is based on a pedagogical subject. Returning to the problem of library's humanization, all the principles of reading activity of university students are summarized.
\end{abstract}

Keywords - university libraries, humanitarian technologies, reading activity, book communication, library-pedagogy, library and pedagogical resources.

\section{INTRODUCTION. HUMANIZATION OF UNIVERSITY LIBRARY UNDER INFORMATION CULTURE}

Reading activity's organization takes place in Informationintellectual center in the Scientific library of Ural State Pedagogical University It is determined principally by the specific of university's educational space. It includes professional vocational guidance. Future teachers should increase their intellectual-emotional outlook. They get experience accumulating values. It concerns classical literature, culture, art. An academic library is a university library center. It should provide an educational process with information. It is a technological component of the library. Informational communication is impersonal. It is the process of information sharing. However, leading professionals underline that the modern library has digital access to information. The humanitarian function of the library should be increased. Book communication is understood as interrelationship and the process of communication, based on the work with book. There are a lot of technologies. But it is necessary to cope with it. We should motivate people to get information through books. (S.A. Basov, A.N. Vaneev, A.V. Sokolov). What do relevance and sense of «humanity vector» (I.I. Tichomirov) in the library of a pedagogical university include? How to create the strategy and practice of work with the readers in aspiration? «To organize their activity in such way that a center of «library universe would be» a human» [1].

The humanistic component and the strategy of library's activity of the university should become the ideologically conditioned mission of the pedagogical university. Humanistic component is aimed at the general cultural development. This cultural development broadens students' humanistic outlook. Also their universal reading skills are developed. It is important that in modern educational environment reading is actualized as the leading way of knowledge of the world. We define ourselves. The relationship between people should be dialogic. Reading activity is regarded as book communication. It has a personal process (A.V. Sokolov) [2]. This activity includes the process of sense formation and increases new senses, contained in reader's texts. The process of sense formation is realized through interpretation and discussion with other people. Such reading communication and its goals are formed by the priorities of socially educational work of the pedagogical university. This reading communication is focused on learning significant spiritual society's experience and culture (professional-pedagogical, patriotic civic, aesthetic directions and others). 
Dialogue approach in education should be implemented into librarian activity. This approach is supposed to overcome monologue narration and statements. It misleads the reader into a meaningful context. The participants should ask and answer the questions (M.M. Bachtin, V.C. Bibler) in internal and external dialogue. It is endless flow of meanings and senses. It helps to get cultural values.

Organizing activity through the books, an integrative approach should be used. It lies on the basis of interpenetration of goals, tasks of educational establishments and culture; union of different life material and construction of actual content of book communication. This approach directs the process of reader's sense formation. We apply the methods and technologies of activity of related fields of knowledge and education for achieving cross-curriculum result. This result may be personal, social, professional.

The ideas of resource approach in pedagogy are closely related with the development of human's personal resources. A human uses his real asset for successful achievement of the goal. Also the human strengthens resources providing the process of one's development (L.I. Kluchkova, V.M. Lizinsky, T.A. Tsetsorina). Management of the library-pedagogical resource supposes tools' accumulation and differentiation. It is necessary to mention determination and influencing factors on the personality in book communication, actualization and generalization of value-sense content of classical literature compositions. Management includes highlighting functional assignment of each resource component, establishing their interconnections and methods of activity with the reader. Reader's potential becomes the resource in personal sense. This potential passes to the active state only under specially created necessary conditions. It happens in the process of development due to the activation of inner possibilities. This shift for revealing actual information needs stimulation, facilitation. It is important for teacher's self-realization.

Considering the strategy of library humanization, we underlined the most perspective approaches of humanitarian education. They are anthropocentric, applied in the activity of USPU library. These approaches are capable to strengthen content-sense component of book communication in the activity, involved in the education of young people. This strategy includes dialogical, integrative and resource approaches. These approaches help to negate appearing reduction and simplification of senses which exists in mass and informational culture. Such approaches are perspective considering the fact, that library work reveals the problem of indirectness of the influence of negative factors on children' and teenagers' reading. Also «close to the reader» forms of interaction, computer technologies for search, exchange and systematization information are used. The interest for reading should be raised through the practice of reading and prism of dialogue. It includes thoughtful work with the text, literature development, comprehension the peculiarities of language mean and sense of the composition which make positive effect on quality of reading.

Humanitarian approaches in education such as methodology reveal that potential of library-pedagogy in the development of children' and teenagers' reading is not learnt 
enough in current time. Such approaches produce innovational personally-oriented technologies, forms and methods. They are combined with the traditional methods. The purpose is to attract youth to the meaning reading. Introduction of information technology cannot solve all library problems [6].

\section{INNOVATIVE WORK. LIBRARY-PEDAGOGICAL RESOURCE IN ORGANIZATION OF BOOK COMMUNICATION WITH THE READERS}

Development of meaning reading, promotion students' interest in classical literature are the central problems of entering the book communication. Education and adding new senses are closely connected with the reader's motivation, stimulation of development of their interests and skills. Technologies and forms of development of creative reading, deep reading are applied. Dialogical methods of children's and youth' attraction to the qualitative reading of classical literature are used. Classical literature contains a lot of meanings, senses and interpretations. It has spiritual potential and dialogicity.

Taking into consideration the approaches mentioned above, the library's specialists must reveal, develop and learn library-pedagogical resource. Library specialists should create special conditions for promotion reader's activity and selfrealization. Students should be active participants of social and educational interaction. The learning process is aimed at the revealing student's abilities and possibilities. Educational and motivating functions of library's humanitarian technologies dominate. Their stimulating function is in the sphere of reading's development. These functions are revealed only in the process of face to face communication. They are used as «medium» of education and culture (S.A. Basov).

Taking into consideration the formation of the strategy of university library's humanization, we consider that librarypedagogical resource should be understood as internal and external sources. We use tools and methodological aspects for positive changes of personality. They have scientific potential and positive experience of library work with the reading audience. The idea of library-pedagogy, pedagogical approaches, methods and technologies in projecting the programs of reading's promotion is applied. Means of book culture: material, documental, fond and electronic technical resources, potential of interaction with the university's faculties are presented.

Pedagogical, social, spiritual resources of book communication in the library are regarded as the factors of formation the readers' imagination. They are aimed at learning the eternal values and production of new personal senses. They are depicted in literature, culture. They are considered to be important spheres of spiritual life of society (resource approach in the educational process).

For example, methodological potential of the librarypedagogy is inexhaustible. The accents and principles of activity are changing. The reader, participant becomes the center of the educational process. The reader's interests and spiritual needs come first. The pedagogical aspect in the strategy of organization of work with the reader adds necessary effective mechanisms. They are used for taking active reader's position instead of passive one. These mechanisms include influence, interaction, dialogue, reflection.

In general, it should be mentioned about educational and up-bringing activity, based on the organization of work with the book in the library as special place. The library is full of senses of culture. A modern specialist in the sphere of reading is considered to be a facilitator, mediator. This specialist makes the participant interact actively with the book. The library specialist makes students get acquainted with the heroes and ideas, makes a dialogue with the author and senses of the text of the composition. It is a specialist possessing modern technologies of book's promotion and organization of communication with different categories of readers.

\section{RESULTS \\ LIBRARY-PEDAGOGICAL TECHNOLOGY}

Humanitarian technologies in the library sphere, directed at the human's development and extension of its possibilities. They include the acquisition of classical ethic and aesthetic values. Humanitarian technologies in the university's library are the tools of revealing, union and streamlining of resources (librarian and pedagogical). Humanitarian technologies make influence on personality and create conditions for human's self-realization.

In the professional sphere library technology is considered as the complex of means for achieving goals and content of library activity. Contrast and clarify innovational effective definition of integrative library-pedagogical technology. We consider the library-pedagogical technology to be projection and reproduction of actions. These actions are aimed at the consistent realization of humanitarian principles of work in book communication with the readers. These actions can be observed in the interconnection with presentation of characteristics of appropriate organizational forms, special methods, means and criteria of evaluation of solving the set task. Library-pedagogical technologies in work with the reader based on the using traditional and innovative valuesense forms and methods of organization students' interaction. It is necessary to satisfy students' intellectual-spiritual needs, means of involvement in active work with the book, communication about the content of classical and editorial text, phenomenon of social life, culture. Creative activity of participants of communication is strengthening, working with meanings and senses in dialogue and discussion formats.

Training youth through books, we developed the author's library-pedagogical technology of organization of reader's activity and selected forms and methods of communication with the readers. These forms and methods strengthen the process of sense-formation through the book communication. We developed the technology of literature room-discussion aimed at the increasing activity and students' independence in different types of reading activity. 
The concept «literature room-discussion» dates from the 18th century. It is a cultural phenomenon, creative event, united by common theme and literature task. Literature roomdiscussion, as a rule, is based on the pre-established scenario. This scenario supposes the organization of perception the art material and communication. The participants read poems and prose, discuss composition, talk to the invited author, sing, organize theatre perfomances. The main goal of literature room-discussion is organization of creative space for the common deal, communication and development. Considering this fact, we highlight three tasks: communicative, cognitiveaesthetic and spiritual and moral.

Projecting the thematic room-discussion with the students, the stages of interaction are regarded and selected. It also includes meaningful forms of communication and creativity, mechanisms of readers' involvement into co-emotional experience, co-action, discussion. It allows students expressing their thoughts. Also they can be heard. It means that special attention of librarian-teacher is paid to the interactive forms of work with the book, communication with literature composition and art, learning significant spiritual experience. Effective book communication supposes that on the basis of participants' interaction there is a classical text, the idea of the composition, spiritual experience, the writer's personality, cultural-historical and actual context, meanings' interpretation. It is important to create the atmosphere of trustful communication, reflection, discussion. Creative reading «generates new reality» [4].

The first stage is identification, selection of means and creation of unique library-pedagogical resources. It is regarded as special event-meeting. It begins with the primary development the aspects of the theme, highlighting the key spiritual-moral idea together with the readers, students and teachers. It is necessary to choose the compositions of poems and poetry, art and music accompanying and deepening the theme. On this stage it is important to read and to focus on meaningful lines of composition/literature compositions, taking into account pedagogical and spiritual and moral point of view. The original scenario is creating.

- The second stage is development of the scenario, immersion, clarification and preparation of materials for literature room-discussion. The problematic is discussed with the participants. The literature fragments are selected, the key sense events are developed, questions for discussion are prepared. It updates personal significance of event for every participant. Literature material is collected. We discuss this material, find musical accompaniment and decorations.

- The third stage includes the dialogue with the literature composition. Deepening of the senses of the learnt content begins. It can be regarded as «hermeneutic circle». It is reading and reenactment by the artists, using the method of «loud reading» and «artists' trying outs». Participants using these techniques are involved and adapted in performance. They take part in theatricalizing of fragments. Library collaborates with the group of social theatre. The methods of theatre pedagogy are used in training. It is of great importance.

- The fourth stage is public «discussion club». This club requires great attention to the details: motivation and problematic material, putting the open-ended questions. It is a technique of intellectual exercise with using writer's utterances and quotations, modelling work in groups, constructing role and creative tasks, methods of discussion's promotion and generalization. Experts make speech at this stage.

- The fifth concluding stage is «spiral reflection». The key moral idea for the meeting is experienced and understood. It is taken hold on the emotional-intellectual level in contact with art material of high aesthetic quality and significance. This stage deepens internal and external readers' dialogue in the work with new senses «in the human dimension. Students are offered literature-musical composition, piece of feature film, collective performance of the song.

It should be stressed important components of roomdiscussion. They are the following: cross-cutting of conductors, moderators (promoting, summarizing function in the dialogue) and discussion's expert assessment. In the dialogue the emphasis is on spiritual and moral content integration with life material. The system of ideas and values is also taken into consideration. The impact of the target is obvious. The reader's strategies are formed through meaningful reading. It happens due to the fact that classical literature is full of humanistic meanings.

One of the main directions of humanitarian activity of Scientific library is professionally-oriented pedagogical direction. It contributes to the education of students. The process is organized by educating students in the values of humanism.

Pedagogical thematic and conditions of learning moral and ethical values in the teacher's work, formation of his outlook were revealed in literature room-discussion, dedicated to the creative work the masters of prose V. Rasputin, C. Aitmatov. These events were held in the memorable dates of outstanding writers. Literature material is a focus of attention. Literature material includes short stories, novels. Ideas and conflicts and the ways of their solving by the author are demonstrated and discussed. We organize discussion and try to understand the main idea. We also pay attention to highlighting and understating the author's attitude to the main characters. Social-pedagogical problematic is also discussed. We learn deep and inexhaustible humanistic and spiritual literature material. It includes stories «French lessons» and «The first teacher», which became the sense axe of traditional dialogue with the readers. These events were held back-to-back with the International Teacher Day.

Great attention is paid to the students' events with pedagogical direction. The idea and meaningful core are forming the personality's attitude to the future profession. Such events motivate students to take an active part in social life. We rely on the means of book communication on the basis of reader's skills. We choose the best compositions of Russian literature for the students. During our lessons we use active forms of interaction on the basis of ethical and aesthetic humanistic values.

In technology of literature room-discussion of pedagogical thematic the quality of intellectual-classical material, personal 


\section{CONCLUSION}

Educational nature on vocational training of students is of great importance for the pedagogical university. Principles of social responsibility of university's library are positive factors. They influence scientific library's activity. The scientific library is regarded as educational, informative center. It is a space of book's culture. In the library you can read thoroughly. You get fruitful creative interaction with readers. It is a useful practice for future teachers.

Solving the problem of library's humanization, we have generalized the principles of organization of readers' activity in the library of the pedagogical university. These principles may be applied in other libraries:

- principle of unity of informative-educational environment «library - university - school». There are different categories of readers: students, pupils, teachers;

- $\quad$ principle of book communication is realized through development and implementation of humanitarian approaches and technologies. The reader gets acquainted with nonfiction and artistic works. personally-oriented kinds of readers' activity are used. Including in valuable-based activity through productive forms is used;

- $\quad$ principle of union of library-pedagogical resource. (Live communication. Our cultural universals are realized through live communication) (S.A. Basov).

These principles of work with the readers, increasing their intellectual, creative, personal activity. They provide and determine established person's centrality. These principles increase students' spiritual needs and possibilities.

Based on humanitarian approaches, technologies, principle of unity of educational environment, we consider that effectiveness of organization of readers' activity in the library should include not only sectoral library indicators. It includes additional attendance, coverage of participants. Also the criteria of qualitative assessment of the processes of sense formation and self-realization of students should be studied. For example, the students' reading skills can be assessed in term of the following criteria. They are the following: cognitive needs and abilities, motivation to creative activity (awareness of goals and interest, ability to reflection, initiative in solving creative tasks, dialogical communication's skills, openness to positive and social experience). Also complex solving of tasks of professional-pedagogical education can be mentioned.

Interdisciplinary approaches of humanitarian education, strengthening valuable, meaningful components in work are essential. They are connected with children's and youth's reading. These approaches are not used enough in library operations. Their integration depends on rethinking of librarian's function. The librarian should be a teacherlibrarian, facilitator and mediator in the person's dialogue with the book. Literature and culture have a lot of different meanings and senses. Updating of humanitarian technologies in the library is connected with the changes of ideological and philosophical basics of concept of readers' activity organization under the conditions of digital electronic 
communication. Librarian «carries out important social mission». This person gets students cultured, implements mediation between the reader and book» [8].

In practice-oriented research the promise of dialogical, integrative approaches in developing the basics of strategies of humanization of the university library and library-pedagogical technology of communication is shown. The resource approach is based on the principles of reading activity's organization in the university library. We take into account facilitation in pedagogy and library. These approaches strengthen the effectiveness of person's interaction with meanings of works of literature and art. The attention should be paid to the age specific of youth. The lessons can be different (literature room-discussion, non-formal communication, role-play game, creativity, self-realization).

For USRU library union between library and pedagogical resources is a way for realization the librarian humanism (A.N. Vaneev). The humanism is an inspiring idea of its development as social-cultural institute and center of reading, communication, creativity. Acting author's technologies of organization reading activity are methods of participants' interaction in humanitarian model of opened library. They have a special meaning. Opened libraries give the readers possibility to master reading. Reading includes efforts, creativity and social experience. It is necessary to focus information and communication technology on the realization of aesthetic, axiological, moral categories of humanism.

Research helps to reveal possibilities and deep the content of book communication with the readers. Our readers are future teachers. They will have to develop children's reading culture in the context of modern technologies and reading practices. Reading practice depends on the age-group. Reading practice includes event, game, creativity, dialogue, competition. It will serve for clear decision of methodological and organizational-technological teacher's tasks in the sphere of innovations. Reading practices stimulate and develop reading activity. Meaningful methods' for successful children's socialization should be considered. Considering the development of information technologies, it should be considered. We should understand that educational environment has an impact on personal development. There are a lot of information technologies, but library has not lost its humanistic appointment.

The generalization of theory and practice of work in the sphere of enrichment of forms reading activity is regarded as a necessary condition of development humanitarian noninstitutionalization of the library. It is important in the innovative educational environment of the university. It is contrasted to non-book communication, impersonal communication. Such types of reading as skimming, superficial, moving reading are prevailing. The users address more often to the digital content, distant access points to the information. They try to achieve the «balance» of all modes of interaction with the readers in a pedagogical aspect.

\section{References}

[1] S.A. Basov, «Humanism: in search of an impeccable system of value», Librarianship, vol. 17 (154), pp. 16-19, 2011.

[2] A.V. Sokolov, The library and humanism: the mission of the library in the global technological civilization. St. Petersburg, 2012, pp. 390-395.

[3] E.O. Galickih, «Life-creating workshops as an innovative technology of event education», Pedagogical image, vol. 1 (30), pp. 49-54, 2016.

[4] I.I. Tihomirova, «New vector for the development of Russian libraries, or to teach humane thinking», Librarianship, vol. 17 (154), pp. 20-23, 2011.

[5] N.V. Lopatina, «Library professions in the information society», Bulletin of the Mosc. Univ. of Culture, vol. 5 (67), pp. 186-189, 2015.

[6] A.N. Vaneev, «Library technologies: from the cultural revolution to the information society», Librarianship, vol. 5 (215), pp. 26-31, 2014.

[7] T.B. Markova, «Reading as an integral way of life: a paper book and / or electronic text», Librarianship, vol. 4, pp. 7-15, 2013.

[8] I.I. Tihomirova, Library pedagogy or book education. St. Petersburg, 2011, pp. 81-88.

[9] S.I. Fedenko, «Library pedagogy», Bulletin of the Donetsk Ped. Inst., vol. 2, pp. 205-209, 2017.

[10] L.N.Yakina, «Humanitarian technologies of civil-patriotic education of readers in the sociocultural activities of the Ural State Pedagogical University Scientific Library», Bulletin of soc. and human. Education $\begin{array}{llllll}\text { and } & \text { science, } & \text { vol. } & 1, & \text { pp. 25-33, }\end{array}$ 